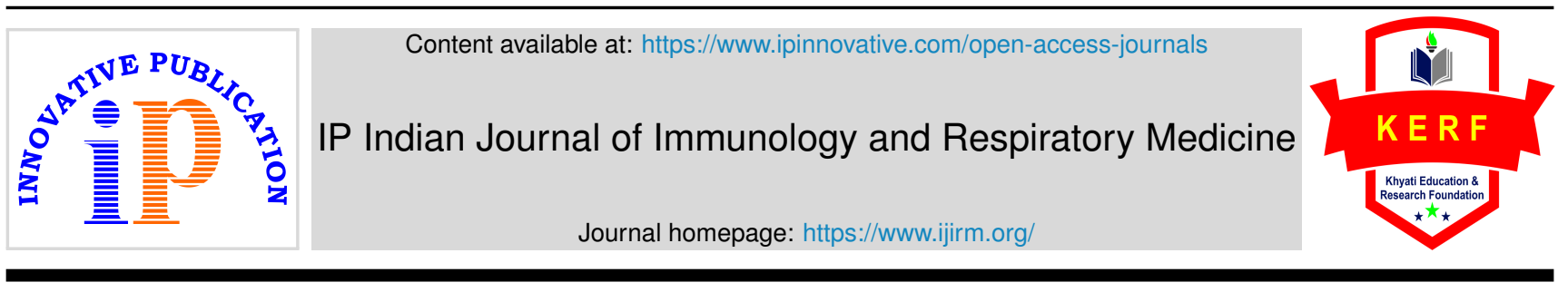

Original Research Article

\title{
A study on overview of asthma-chronic obstructive pulmonary disease overlaps among patients with obstructive airway diseases
}

\author{
Are Suryakari Sreekanth ${ }^{1}$, P Ajoy Kumar ${ }^{1, *}$ \\ ${ }^{1}$ Dept. of Pulmonary Medicine, Kurnool Medical College, Kurnool, Andhra Pradesh, India
}

\section{A R T I C L E I N F O}

\section{Article history:}

Received 09-03-2021

Accepted 16-06-2021

Available online 07-06-2021

\section{Keywords:}

Asthma and Chronic obstructive pulmonary disease

Obstructive airway diseases

\begin{abstract}
A B S T R A C T
Background : Asthma and chronic obstructive pulmonary disease (COPD) are different disease entities. They are both clinical diagnoses, with diagnostic tools to discriminate between one another. There is a need to re-evaluate the concept of asthma and chronic obstructive pulmonary disease (COPD) as separate conditions, and to consider situations when they may coexist, or when one condition may evolve into the other.

Materials and Methods: A prospective study included 70 patients with chronic airway diseases who were classified into three groups (COPD, asthma and ACO). They were selected from Department of Pulmonary Medicine, Kurnool Medical College outpatient clinic during the period from January 2019 to December 2019, where patients with COPD and ACO were diagnosed according to GOLD guidelines and patients with asthma were diagnosed according to GINA guidelines. Patients enrolled in the study were subjected to full history taking, clinical examination, full laboratory examination, plain chest radiography, spirometry before bronchodilator and after bronchodilator administration (reversibility test) and sputum analysis for counting eosinophils cells.

Results: This study was conducted on 70 patients with chronic airway diseases (COPD, asthma and asthma COPD overlap) were selected. It included $47(67.1 \%)$ males and $23(32.8 \%)$ females. In our study, 30 $(42.8 \%)$ patients as having COPD, 19(27.1\%) patients were diagnosed as having asthma and 21(30\%) patients were diagnosed as having ACO. Regarding the age difference between groups, it was found that patients who were diagnosed as having ACO were older than asthmatic patients with mean age of $49.43 \pm 5.83$ and $47.23 \pm 6.73$ years, respectively. The men age of patients with COPD was $57.32 \pm 6.74$ which was older than both ACO and asthmatic patients.

Conclusion: ACO represents a large percentage among patients with obstructive airway diseases. It shares some features of asthma such as atopy and positive sputum eosinophilia, and some features of COPD like old age of presentation and positive smoking history.

(C) This is an open access article distributed under the terms of the Creative Commons Attribution License (https://creativecommons.org/licenses/by/4.0/) which permits unrestricted use, distribution, and reproduction in any medium, provided the original author and source are credited.
\end{abstract}

\section{Introduction}

Asthma and chronic obstructive pulmonary disease (COPD) can be effectively recognized at their limits, numerous patients show highlights of the two illnesses and are alluded to by clinicians as having "asthma/COPD." The declaration of infection was controlled by both endogenous and exogenous elements, asthma and COPD have normal starting points. In particular, they

\footnotetext{
* Corresponding author.

E-mail address: assreekanth9563@gmail.com (P. A. Kumar).
}

unequivocally underscored the requirement for cautious phenotyping of patients before rashly allotting them a sickness mark. ${ }^{1}$ Lately, there has been expanded acknowledgment of the clinical cover among asthma and COPD, called asthma-COPD overlap syndrome (ACOS). ${ }^{2}$

Nonetheless, the term ACOS stays dubious, without a settled upon definition. ${ }^{3}$ For instance, it stays indistinct if ACOS is an alternate sickness showing in never-smokers with asthma, or rather distinguishes the advancement of serious asthma after some time. ${ }^{4}$ In spite of our restricted 
arrangement, ACOS is progressively perceived as a clinical substance particular from asthma or COPD, yet with covering highlights. ${ }^{5}$ A few investigations have shown that patients with ACOS have more dynamic or serious infection, more noteworthy grimness and mortality, and lower personal satisfaction. ${ }^{6}$

They characterized "ACOS-bronchodilator responsive" (ACOS-BDR) based on a background marked by asthma or feed fever, the presence of aviation route obstacle with huge bronchodilator responsiveness, and insignificant $(<15 \%)$ emphysema present on figured tomographic (CT) chest pictures. "COPD with emphysema" was characterized as (1) a background marked by asthma or roughage fever, (2) airway route impediment without bronchodilator reversibility (post-bronchodilator change in FEV1: $<400 \mathrm{ml}$ and $<15 \%$ ), and (3) the presence of emphysema on chest CT imaging ( $>15 \%$ of lung).

\section{Materials and Methods}

A prospective study included 70 patients with chronic airway diseases who were classified into three groups (COPD, asthma and ACO). They selected from Department of Pulmonary Medicine, Kurnool Medical college outpatient clinic during the period from January 2019 to December 2019, where patients with COPD and ACO were diagnosed according to GOLD guidelines 7 and patients with asthma were diagnosed according to GINA guidelines. $^{8}$

\subsection{Inclusion criteria}

Patients of either gender between age group 30 to 60 years, Patient willing to give informed written consent.

\subsection{Exclusion criteria}

Restrictive lung disease, bronchiectasis, COPD exacerbation and vocal cord dysfunction.All patients are subjected to full history taking, clinical examination, full laboratory examinations, chest radiography, spirometry and post bronchodilator reversibility test was performed and sputum analysis, where induction of sputum by hypertonic saline or mannitol is done by a trained staff with strict airborne respiratory precautions. The procedure should be stopped when the patient has produced $5-10 \mathrm{ml}$ of sputum, about $15 \mathrm{~min}$ of nebulization is reached. The patient complained of dyspnea, chest tightness or wheeze. Sputum processing and staining and count were done with assessment of sputum eosinophil's. ${ }^{9}$

\subsection{Statistical analysis}

Information were genuinely portrayed as far as mean $\pm \mathrm{SD}$, middle and reach, or frequencies (number of cases) and rates when proper. Examination of mathematical factors between the investigation bunches was done one path examination of difference test with post-hoc numerous twobunch correlations. For contrasting straight out information, $\chi 2$-test was performed. $\mathrm{P}$ value under 0.05 was considered measurably huge.

\section{Results}

This study was conducted on 70 patients with chronic airway diseases (COPD, asthma and asthma COPD overlap) were selected. It included $47(67.1 \%)$ males and $23(32.8 \%)$ females [Table 1].

Table 1: Sex distribution among the study group

\begin{tabular}{lccc}
\hline & Males & Females & Total \\
No. of patients & 47 & 23 & 70 \\
Percentage & 67.1 & 32.8 & 100 \\
\hline
\end{tabular}

Table 2: Classification of study groups based on final diagnosis

\begin{tabular}{lcccc}
\hline & COPD & ACO & Asthma & Total \\
No. of patients & 30 & 19 & 21 & 70 \\
Percentage & 42.8 & 27.1 & 30.0 & 100 \\
\hline
\end{tabular}

ACO: Asthma chronic obstructive pulmonary disease overlap; COPD: Chronic obstructive pulmonary disease.

In our study, 30 (42.8\%) patients as having COPD, 19 (27.1\%) patients were diagnosed as having asthma and 21 $(30 \%)$ patients were diagnosed as having ACO (Table 2).

Table 3: Age differences between the study groups

\begin{tabular}{lccc} 
& COPD & ACO & Asthma \\
$\begin{array}{l}\text { No. of } \\
\text { patients }\end{array}$ & 30 & 19 & 21 \\
Mean \pm SD & $57.32 \pm 6.74$ & $49.43 \pm 5.83$ & $47.23 \pm 6.73$ \\
\hline
\end{tabular}

Regarding the age difference between groups, it was found that patients who were diagnosed as having ACO were older than asthmatic patients with mean age of $49.43 \pm 5.83$ and $47.23 \pm 6.73$ years, respectively. The men age of patients with COPD was $57.32 \pm 6.74$ which was older than both ACO and asthmatic patients (Table 3 ).

Table 4: Comparison of studied groups regarding history of atopy

\begin{tabular}{|c|c|c|c|}
\hline & \multicolumn{3}{|c|}{ Diagnosis } \\
\hline & $\begin{array}{l}\text { COPD } \\
(\mathrm{N}=30)\end{array}$ & $\begin{array}{c}\mathrm{ACO} \\
(\mathrm{N}=19)\end{array}$ & $\begin{array}{r}\text { Asthma } \\
(\mathbf{N}=21)\end{array}$ \\
\hline \multicolumn{4}{|l|}{ No } \\
\hline Count & 24 & 8 & 4 \\
\hline$\%$ within diagnosis & 80.0 & 42.1 & 19.0 \\
\hline \multicolumn{4}{|l|}{ Yes } \\
\hline Count & 6 & 11 & 17 \\
\hline$\%$ within diagnosis & 20.0 & 57.8 & 80.9 \\
\hline
\end{tabular}

In Table 4, in our showed the comparison of groups regarding history of atopy. We found that $57.8 \%$ of ACO 
group, $80.9 \%$ of asthma group and $20.0 \%$ of COPD group had a positive history of atopy.

Table 5: Comparison of study groups regarding sputum eosinophils

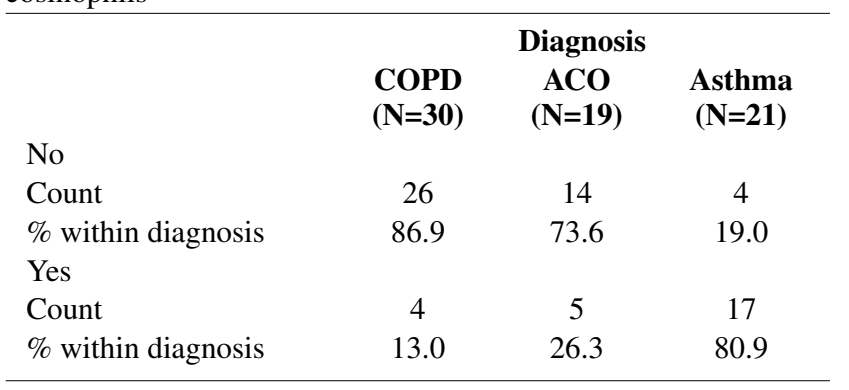

Comparison of study groups regarding sputum eosinophils revealed that $26.3 \%$ of ACO group, $80.9 \%$ of asthma group and $13 \%$ of COPD group had positive sputum eosinophils. (Table 5)

\section{Discussion}

Yet those with ACOS would do well to lung work, they had relative earnestness and repeat of escalations stood out and patients from COPD. Unquestionably, when adjusted to FEV1\% expected despite age, race, sex, BMI, complete pack-years, and current smoking, subjects with ACOS will undoubtedly experience outrageous and constant escalations. Thusly, the makers deduced that bronchodilator responsiveness and nonappearance of basic emphysema on CT sifting can perceive patients with ACOS, who emit an impression of being a high-risk bundle with undeniable clinical features. ${ }^{10}$

The meaning of this examination is that it used instantly available estimations to portray ACOS in a COPD people. In spite of the way that spread cut off was not uncovered, estimation of emphysema on chest CT checks got together with history and spirometry give a reasonable method to manage perceiving ACOS-BDR from COPD with emphysema.

Despite the fact that various experts have tried to describe ACOS in an asthma people dependent on pathophysiological disclosures, a pack examination of the Severe Asthma Research Program associate used clinical measures to portray five indisputable social occasions. ${ }^{11}$ As differentiated and the other four social occasions, Cluster 5 subjects were more like those with COPD than those with asthma; they were more settled with more genuine fixed breeze stream obstacle, had longer disease length, less atopy, and mixed sputum eosinophilia and neutrophilia. ${ }^{12}$ They in like manner had more constant signs and albuterol use, with more conspicuous comorbidities, and higher clinical benefits use. According to various perspectives, Cluster 5 subjects may truly address patients who can be better depicted as having ACOS. Whether or not a given patient has fantastically COPD with asthma features, or asthma with COPD features, the practicing clinician needs consistent plans to total patients and choose the most legitimate treatment.

Of 10,192 enrolled subjects, 385 fulfilled guidelines for ACOS-BDR and 620 met rules for COPD with emphysema. Subjects with ACOS were younger, bound to be African American, and had higher weight record (BMI), and will undoubtedly be current tobacco smokers. A large portion of subjects with ACOS met measures for GOLD (Global Initiative for Chronic Obstructive Lung Disease) COPD earnestness grade B. ${ }^{13}$

Another critical finding in the examination by Cosentino and accomplices is related to the GOLD 2011 reality grade. Very nearly one-part of subjects with ACOS had grade B sickness, showing a critical level of results and contamination feebleness, paying little mind to having better expiratory flying course work on spirometry when stood out from subjects with COPD. Notwithstanding the way that subjects with COPD had smoked even more enthusiastically as assessed by cigarette pack-years, subjects with ACOS were extensively more obligated to be current smokers, which could be driving the letter GOLD assessment B task. Subjects with ACOS furthermore had a higher prevalence of comorbidities, for instance, rest apnea, diabetes mellitus, hypertension, and hypercholesterolemia when appeared differently in relation to patients with COPD. Having a higher BMI, to move toward strength (29.6 kg/m2), and a more conspicuous inescapability of gastroesophageal reflux contamination raises issues related to eat less carbs, lifestyle, and food true to form allies of ACOS pathophysiology. ${ }^{14}$

Finally, paying little heed to having more limited disorder, subjects with ACOS were less disposed to use long-acting $\beta$-agonist, a long-acting muscarinic enemy, or a blend took in corticosteroid/long-acting $\beta$-agonist than those with COPD. Whether or not (and how much) this qualification in treatment is adding to the differentiations in signs and intensifying earnestness is not clear from the assessment.

Until more convincing examinations are done, it is reasonable to appraise that solidifying clinical history, markers of atopy or sensitivities (e.g., skin testing, IgE), physiology (e.g., spirometry, bronchodilator response, PC20 bronchial test, air-getting), imaging (e.g., chest CT, appealing resonation imaging with hyperpolarized gases), biomarkers of bothering (e.g., inhaled out nitric oxide, blood and sputum eosinophils, periostin, C-responsive protein), and conceivably inherited testing (e.g., alpha-1-antitrypsin) could help portray patients as having asthma, COPD, or ACOS. In any case, challenges stay as not these limits are open for clinicians. Whether or not they become available, the load to patients and related costs may confine their wide execution in clinical dynamic. ${ }^{15}$ Molecular phenotyping is rapidly advancing and may after a short time offer spot 
of-care, sensible scientific instruments to help clinicians in making more unequivocal decisions that could enlighten the pathophysiology of avionics course contamination and help control its treatment. ${ }^{16}$

Later on, the usage of indicative terms, for instance, "asthma," "COPD," and "ACOS," will most likely offer course to the truly uniting assurance of obstructive aviation route sickness (OAD), as at first proposed by Professor Orie and partners. OAD would be moreover laid out dependent on nuclear phenotyping, genomic, and structures science moves close, in blend in with more standard clinical and physiological limits.

\section{Conclusion}

ACO addresses a huge rate among patients with obstructive aviation route illnesses. It shares a few highlights of asthma like atopy and positive sputum eosinophilia, and a few highlights of COPD like mature age of show and positive smoking history.

\section{Acknowledgement}

None.

\section{Source of Funding}

No financial support was received for the work within this manuscript.

\section{Conflict of Interest}

The authors declare that they have no conflict of interest.

\section{References}

1. Postma DS, Weiss ST, van den Berge M, Kerstjens HAM, Koppelman GH. Revisiting the Dutch hypothesis. J Allergy Clin Immunol. 2015;136(3):521-9. doi:10.1016/1.jaci.2015.06.018.

2. Global Initiative for Chronic Obstructive Lung Disease. (2017) Global Strategy for Diagnosis, Management and Prevention of COPD. Available at URL:- https://goldcopd.org/. Last accessed 20201 on May 1.

3. Gibson PG, McDonald VM. Asthma-COPD overlap 2015: now we are six. Thorax. 2015;70(7):683-91. doi:10.1136/thoraxjnl-2014-206740

4. Sköld CM. Remodeling in asthma and COPD - differences and similarities. Clin Respir J. 2010;4(1):20-7. [oi:10.111/].17526पपर.20ण0णप3x

5. van Boven J, Román-Rodríguez M, Palmer JF, Toledo-Pons N, Cosío BG, Soriano JB, et al. Comorbidome, Pattern, and Impact of AsthmaCOPD Overlap Syndrome in Real Life. Chest. 2016;149(4):1011-20. do1:10.1016/1.chest.2015.12.002

6. Christenson SA, Steiling K, van den Berge M, Hijazi K, Hiemstra PS, Postma DS, et al. Asthma-COPD Overlap. Clinical Relevance of Genomic Signatures of Type 2 Inflammation in Chronic Obstructive Pulmonary Disease. Am J Respir Crit Care Med. 2015;191(7):758-66. 10i:10.1164/recm.201408-145800

7. Barnes P. Therapeutic approaches to asthma-chronic obstructive pulmonary disease overlap syndromes. J Allergy Clin Immunol. 2015;136:531-45.

8. Bateman ED, Reddel HK, van Zyl-Smit R, Agusti A. The asthma-COPD overlap syndrome: towards a revised taxonomy of chronic airways diseases? Lancet Respir Med. 2015;3(9):719-28. do1:10.1016/s2213-2600(15)00254-4.

9. Alshabanat A, Zafari Z, Albanyan O, Dairi M, FitzGerald JM. Asthma and COPD Overlap Syndrome (ACOS): A Systematic Review and Meta Analysis. PLoS One. 2015;10(9):e0136065. do1:10.1371/journal.pone.0136065.

10. Cosentino J, Zhao H, Hardin M, Hersh CP, Crapo J, Kim V, et al. Analysis of asthma-COPD overlap syndrome when defined on the basis of bronchodilator response and degree of emphysema. Ann Am Thorac Soc. 2016;13:1483-9.

11. Gelb AF, Yamamoto A, Verbeken EK, Nadel JA. Unraveling the pathophysiology of the asthma-COPD overlap syndrome: unsuspected mild centrilobular emphysema is responsible for loss of lung elastic recoil in never smokers with asthma with persistent expiratory airflow limitation. Chest. 2015;148:313-20.

12. Postma DS, Weiss ST, van den Berge M, Kerstjens HAM, Koppelman GH. Revisiting the Dutch hypothesis. J Allergy Clin Immunol. 2015;136(3):521-9. do1:10.1016/1.jaci.2015.06.018

13. Christenson SA, Steiling K, van den Berge M, Hijazi K, Hiemstra PS, Postma DS, et al. Asthma-COPD Overlap. Clinical Relevance of Genomic Signatures of Type 2 Inflammation in Chronic Obstructive Pulmonary Disease. Am J Respir Crit Care Med. 2015;191(7):758-66. 1010. $164 / \mathrm{rccm} 201408-14580 \mathrm{~d}$.

14. Gelb AF, Nadel JA. Understanding the pathophysiology of the asthma-chronic obstructive pulmonary disease overlap syndrome. $\quad J$ Allergy Clin Immunol. 2015;136(3):553-5. d01:10.1016/].jac1.2015.06.013.

15. Ghebre MA, Bafadhel M, Desai D, Cohen SE, Newbold P, Rapley L, et al. Biological clustering supports both "Dutch" and "British" hypotheses of asthma and chronic obstructive pulmonary disease. J Allergy Clin Immunol. 2015;135(1):63-72. do1:10.1016/].jaci.2014.06.035.

16. Reddel HK. Treatment of overlapping asthma-chronic obstructive pulmonary disease: Can guidelines contribute in an evidencefree zone? J Allergy Clin Immunol . 2015;136(3):546-52. do1:10.1016/].jac1.2015.06.043.

\section{Author biography}

Are Suryakari Sreekanth, Associate Professor

P Ajoy Kumar, Assistant Professor

Cite this article: Sreekanth AS, Kumar PA. A study on overview of asthma-chronic obstructive pulmonary disease overlaps among patients with obstructive airway diseases. IP Indian J Immunol Respir Med 2021;6(2):117-120. 